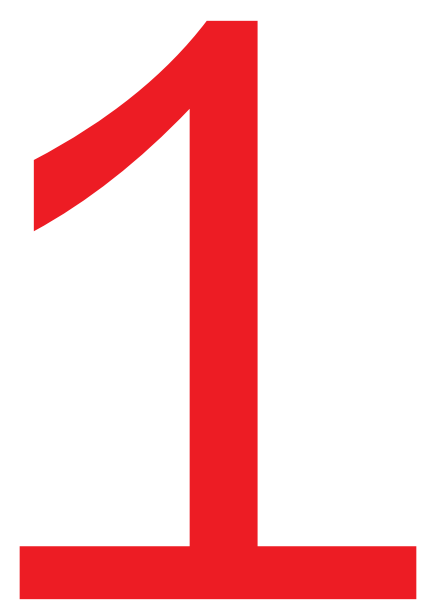

\title{
Abstract
}

Definitions and understandings of the term "community health" are numerous, but generally orient themselves around an expanded understanding of health exceeding biomedical imperatives. Rethinking the conception of community health through a vitalistic approach with the idea of health, and thus the community, at its core allows for a deeper understanding of health experiences' complexity and could eventually inspire practice innovations in community health centers. In this paper, we will present this theoretical conception of health and discuss how it can help to understand the innovative interventions approach conducted within community health centres in Canada. Specifically, the practical implications of this theoretical conception will be illustrated through two Canadian community health centres. A new perspective on health could have numerous implications for health professionals with the development of cutting-edge interventions potentially leading to change benefiting the community, but also for teaching and research innovations empowered by a deeper understanding of the wider story behind health issues.

Key Words community health, health, social norms, vitalism

\section{Practical Implications of Understanding Community Health Through Vitalism in Canadian Community Health Centers}

\author{
ELISABETH BEAUNOYER, VALÉRIE \\ DESGROSEILLIERS, NICOLAS VONARX, \\ \& BERNARD ROY
}

\section{Introduction}

Community health is an interdisciplinary field that refers to a wide variety of realities[1] and overlaps with multiple areas related to health sciences, such as public health, medicine, nursing, psychology, and other social science fields. The multiplicity of community health definitions is probably no stranger to the polysemy and the ambiguity of the notion of health. From the WHO definition[2] to the Ottawa Charter's definition[3] several definitions of health coexist, thereby generating a diversity of applications depending on their area of concern. In an effort to distinguish public and community health, Vonarx and Desgroseilliers[4] propose an epistemological reflection on how we think and construct the idea of health, and contingently the idea of community, by adopting a vitalistic approach drawn upon Georges Canguilhem's work.[5,6] Specifically, this approach acknowledges that we cannot consider health strictly on the basis of absolute benchmarks because of the normalizing effect they have on living conditions. In vitalistic thought, health is argued not as standard to achieve and maintain, but as a condition of existence that needs to be implemented according to its own subjectivity and with respect to the rules of propriety[7] constrained by the belonging to a milieu, understood in the sense of social context or environment. As such, we understand that health is a living condition intimately related to the requirements of the milieu on a social, or even community level, and that its definition and implications are constantly disputed by the milieu, on the one hand, and its subject, on the other hand. This theoretical conception thus rethinks community health in light of a new conception that 
allows for ideologies to reach beyond practical and financial imperatives.

This idea of community health can serve as a mean to better understand what characterize the intervention practices within the Community Health Centres $(\mathrm{CHC})$ and could even aid to distinguish them from mainstream healthcare in Canada. Canadian $\mathrm{CHCs}$ share several similar characteristics including the status of non-profit organization receiving public funding, the provision of comprehensive and integrated primary health care, and community engagement and participation.[8] Indeed, the concept of health used by health care professionals (HCPs) influences their way of looking, talking, hearing and thinking the human existence in the planning of community health-specific interventions. For this reason, thinking critically about a conception of health that stresses its epistemological and ontological grounds proves to be relevant in order to highlight the differences between a community health-related approach to care and a practice stemming from conventional medical thinking. In the first part of this paper, we will summarize the ideas underlying the vitalistic conception of community health as proposed by Vonarx and Desgroseilliers [4] (see the original book chapter for a more in-depth reflection). In the second part, we will illustrate how this theoretical conception of health applies to community health practices in a more intelligible and potentially more operational way. Although, this theoretical conception could arguably suit multiple health systems, this paper will pursue its illustration within a Canadian health care context, the one in which the initial reflection was developed. For this purpose, a short summary of the historical foundations of the Canadian healthcare system and centres will be presented. Then, we will provide two examples of Canadian centres showing how they integrated, or at least partially integrated, a conception of community health, revisited through vitalism.

\section{Rethinking the idea of community health using a vitalistic approach}

In mainstream health care, the biomedical perspective is widely integrated and accepted, according to which health appears to be understood on a binary mode, opposing its presence to the absence of disease. In this paradigm, the benchmarks that identify any pathological sign rest upon norms based on physio-biological and psychic assumptions suggesting a physical and biological body failure expressed in terms of excess or deficiency, or even a quantitative abnormality. Canguilhem introduces this notion of normality as a theoretical unit constructed by the exercise of reason and acting as a reference point in a given space and time.[9] This is what made the assessment of health using measures and variables possible, enabling the documentation of a condition labeled as "normal" or "healthy," as opposed to "pathological." Although various studies in social and human sciences showed that health needs to be thought as a phenomenon that also encompasses subjective and social dimensions (see the work of Herzlich).[10,12] it appears that its biomedical conception prevails for HCPs working in health care institutions and that health is almost exclusively assessed by applying objective standards. Standardizing the organism's biological and physiological aspects supports a vision of health as a state (or multiple states) that needs to be controlled and mastered, or normalized even, by using indicators to measure observable variations and apparent gaps according to objective standards established by medical sciences. Hence, the idea of both control and determinism is fundamental to a biomedical paradigm.

At the turn of the 1960s, a certain idea of community health emerges inside a critical thinking movement about society's medicalization, notably driven by thoughts developed by Ivan Illich in his work Medical Nemesis: The Expropriation of Health.[11] Questioning the biomedical paradigm is at the core of this movement, challenging the fact that health has become - according to the rules of capitalism - market value or goods to be consumed and managed for anyone willing to function within society. As such, Illich emphasizes that health essentially falls under the authority of an overspecialized medical infrastructure organized around technical services and care that strictly target the alleviation of symptoms, and therefore fails to identify the root causes of diseases, and neglects at the same time the influence of human vulnerability.[11] Illich clearly highlights the role of the various social, environmental, and political determinants on people's health while stressing that medicine, as a factor, is far from assuming the lifesaving role it claims to have, not to mention it has been occasionally counterproductive. In the wake of these reflections, further studies highlighted the enhanced role and significative nature of multiple factors impacting health, be it family life, work and housing conditions, lifestyles, social cohesion, socio-economic status, etc. [12].

Canguilhem also articulated thoughts about health, arguing that health is not reducible to an ensemble of measurable and controllable objective factors for it touches upon more than just physiology and biology. Consequentially, the idea of health cannot be comprehended through "a continuum spanning [...] from a complete state of well-being up to death and going through all possible forms of diseases and disabilities [free translation]".[13 p87] For Vonarx and Desgroseilliers,[4] 
casting our eyes beyond a biomedical conception of life involves recognizing and accepting a certain freedom and free will in a subject for whom health is not defined by predetermined biomedical norms. In this context, the vitalistic approach presents itself as an opportunity to understand health differently, in part because it recognizes that forces of life produce instability, and likewise ups and downs change the way we respond to situations. Through the lens of vitalism, health is thus understood as a normative ability and, because of that, as a dynamic and subjective resource as well, or, in other terms, as a condition of life managed by a subject constrained by a milieu.[14]

\section{Normativity}

In community health, the vitalistic ideas that guide the conception of health, as presented by Vonarx and Desgroseilliers.[4] build on the work of Canguilhem and his concept of normativity. This concept suggests that health is not defined by its alignment with the norms, but rather by the individual's normative ability to establish new ones based on the situations they experience and the requirements their living milieu imposes upon them, including how they relate to the people "that matter to them." This existential mode adopted by a living being constrained by their milieu is called an "allure de vie." According to Canguilhem[6], health and disease are inseparable but do not oppose one another, which means that disease is not the absence of health and health is not the absence of disease. Instead, the latter should be understood as an event for it disrupts the existence of a living being. A subjective assessment acts as a barometer of how a given condition is or remains vital for the individual or their community and therefore nourishes their "allure de vie". Pathology arises when a disruption of the "allure de vie" brings about a reduction in their ability to create their own new vital values, norms or milieu, which raise a feeling of being unable to face the movement, and echoes a lack of flexibility and freedom. The idea of vitality (biological life) is thus eminently subjective, resting on qualitative thinking. Therefore, we understand that health can no longer be assessed strictly through the lens of physio-clinical objectivity and that subjectivity, both on the individual and community level, appears to be the sole voice through which feelings about life can be understood.

\section{Health as a Dynamic and Subjective Resource}

According to Vonarx and Desgroseilliers[4], the concern to think health outside of the biomedical spectrum leads us, in the light of Canguilhem's vitalistic thought, to consider health as a dynamic and subjective resource. As such, health is no longer relegated to a condition one can have but is rather understood as a resource that is constantly acquired and that makes sense solely for the individual and their living environment. It allows people to move forward in life with a plan reflecting aspirations that are, above all, personal, [14] and negotiated depending on their social belongings. Everyone has their own conception of health and illness, which results in a paradoxical, complex, and contextual concept that is inseparable from the individual, living and interacting within their milieu.[13] Here, the actor lies at the centre of the equation and their experience of health necessarily becomes subjective, as opposed to the biomedical perspective.

Implicit in the above, conceptualizing health as a normative ability, as well as a dynamic and subjective resource, requires casting our eyes beyond the individual. Indeed, their world is built collectively, within a group, the community or the society to which they belong. The idea of health is constructed upon the relationships we forge with others through negotiation, questioning and intersubjectivity. Health and milieu are not fixed as autonomous notions where the subject acts as a midpoint on an occasional basis, health rather results from the interaction between the subject and their surroundings. Thus, health shall be regarded as an ability that allows any subject to establish new standards for themselves in a complex and dynamic social living environment, by taking into account what makes sense to them, considering that everyone is continually entangled in a network of meanings - a context of existence regulated by rules of propriety enabling the symbolic management of social actors' public appearances while they interact in their living environment.

\section{Community}

Based on the above, thinking the concept of health through the lens of vitalism necessarily involves reconsidering the idea of community. Health, as per the vitalistic approach, is experienced and transformed by the dialogue based on reflexivity and negotiations between the individuals' life plan and their milieu.[4] Therefore, health is undoubtedly related to the social context of emergence, i.e., the community. It constitutes an essential dimension of everyone's existence because everyone is necessarily part of a world, or even several worlds. The community provides rules of propriety and brings forth semantic contents for people to use in their existence. The propriety, as proposed by Mayol[7],

is simultaneously the manner in which one is perceived and the means constraining one to remain submitted to it; fundamentally, it requires the avoidance of 
all dissonance in the game of behaviours and all qualitative disruption in the perception of the social environment (p. 17).

The rules of propriety provide the community with an implied and unwritten form of collective agreement, which is understandable to all individuals through language and behaviour, to which any submission or transgression is necessarily noticeable.[7] The community shares a common will and it is sustained by identity markers that qualify the existential context of living together.[4]

The community carries a unique life experience where universalism and generalization do not have their place. Therefore, the intervention within a community follows a process adapted to the local context that leaves room for creativity and almost always combines sanitary and social issues.[15] This subjectivity implies instability in the responses to interventions approaches that prevents the appropriate prediction and monitoring of the results and that might have unintended effects. In order to work on a normality gap within a community, it is important to understand the norms of propriety in the milieu, which are often very stringent and impactful on the behaviours. That explains why great value is given to listening to the Other in community health, in order to ensure their participation not only in identifying the needs but more importantly, in the transformation process to express this "normativity" both from a personal and collective perspective. Indeed, giving a voice to the social actors must allow the interventions' alignment to the needs expressed by the subjects. We are thus mobilizing "the knowledge, the experiences, the expertise of the concerned actors and citizens by a given reality of health [free translation]" through a shared project producing a normative activity which aims to go beyond the discomforts of existence that are felt, experienced, and believed.[4 p19] The exercise of this normativity is inseparable from a participation that calls for the implementation of conditions that will facilitate empowerment and in which suffering has more to do with a reduced power to act, possibly even its destruction, than physical or mental pain.[16]

Rethinking the idea of community health using a vitalistic approach helps to grasp health as a condition of life that deserves to be understood according to the people's life experiences as living and interacting subjects within complex social relationships.[4] Laying out the theoretical benchmarks raises the issue of whether this perspective is applicable to health care settings or not. This conception of community health could provide a starting point and appropriate tools to identify what characterizes care practices in Canadian CHCs. It is worth noting that while this idea of health and, therefore, of community health, results from a purely theoretical approach, health care practices in $\mathrm{CHCs}$ might be influenced by certain political, pragmatic, financial and ideological factors.[4] Therefore, integrating such a community health approach within $\mathrm{CHCs}$ presents many challenges, mainly due to the paradigmatic orientation that currently dominates the Canadian healthcare system.

\section{Illustrations of the community health vitalistic approach}

\section{Emergence of community health centers in Canada}

The theoretical benchmarks introduced at the beginning of this chapter provide tools to comprehend the current community health practice in Canadian CHCs. Aligned with a legacy of dominance exerted by a growing medical authority over several centuries,[17] the Canada Health Act passed in 1984 greatly contributed to establish the biomedicine predominance in the Canadian health care system, which was essentially built around a hospital-based clinical service offer. Indeed, while the language used in the act's title expresses the idea of health, the terminology used in body of the text rather refers to the medical profession: "to ensure that all eligible residents of Canadian provinces and territories have reasonable access to medically necessary hospital and physician services on a prepaid basis"[18 $p 7]$ We see in this medical mission that the regulating forces immediately associate health to medicine, at the risk of confusing these two terms with one another. The genesis for the community health approach would result in part from "community demands in order to get the best care and [...] services [free translation]",[18 p173] which have foster the emergence of particular organizational structures that apply a health conception that transcends the biomedical perspective and which constitute local front-line service reorganization initiatives.[19] As a result of a critique of the medico-centered model and its inability to respond to the needs of vulnerable populations, the Clinique communautaire de Pointe-StCharles (CCPSC) - one of the first citizens' initiatives of free clinic - emerged in the fall of 1967 in one of Montreal's most disadvantaged neighbourhoods.[20] As the citizens faced a lack of access to primary health care in their neighbourhood, they decided to develop by themselves the medical and illness prevention services they needed, rather than waiting on a system change initiated by the government.[21] In the 1960s, other clinics emerged with similar aspirations, proposing, in a sense, to deploy normativity individually, of course, but more so communally, in order to transform living environments in accordance with the citizens' well-being aspirations. This period marks the birth of a community clinic model governed by the community, one that will set trend in Quebec.

The "local community health services" (CLSCs) were introduced in the 1970s following the recommendations of the Castonguay-Nepveu Commission and found their sources of inspiration in clinics like those of Pointe-Saint-Charles and 
Hochelaga-Maisonneuve in Montreal. However, as soon as they were implemented, the CLSCs' mission was hampered by the physicians' corporations which refused that their members be bound by a wage agreement and, most importantly, to lose control over the medical institutions. In order to counter the deployment of CLSCs on the Quebec territory, the physicians' corporation encouraged its members to disaffiliate from the CLSCs and to create in their vicinity private polyclinics fully controlled by physicians. Consequently, the development of community health care throughout Quebec has been deeply compromised. Today, community action is no longer mentioned in the CLSCs' mission statement and they are not sovereign institutions managed by their own boards of directors.[22] Nonetheless, initiatives going by different names and emerging in a few locations reveal, on the one hand, the vitality of the community health paradigm and, on the other, the resurgence and increase of social inequalities.

In the next section, we will present an illustration of a Quebec $\mathrm{CHC}$, the Coopérative de solidarité SABSA, that partially integrate a community health vitalistic approach, with the deployment of individual and community normativity. A second example can push further forward the reflection by illustrating a partially integrated community health vitalistic approach in a centre outside of the mainstream healthcare. This example is the Maison Michel-Sarrazin, which, from where we sit, illustrates a health care practice that accepts the unique and normative nature of health in the end-of-life experience. The following analysis is not meant to be exhaustive or a perfect illustration of the vitalistic approach, but rather an illustration of the key points in each of these examples.

\section{Individual \& community normativity: The example of the coopérative de solidarité SABSA}

The Coopérative de solidarité SABSA, created in 2011, is another non-profit organization example that has emerged from a critique of both the medical body and the marketing of health. This initiative originates from an awareness on the magnitude of the HCV and HIV/AIDS epidemic among vulnerable populations,[23] and indignation over the response offered by the mainstream healthcare organization[24]. From the start, it has endorsed the mandate to provide services to a vulnerable clientele, whose lack of health care stands out as a health priority, using a "holistic response-centered approach to the global needs of the people integrating physical health, mental health and psychosocial dimension".[24 p7, free translation] The services provided at the clinic are varied (see the website for an exhaustive description [in French only]; www.coop-sabsa.com) including the prescription of diagnostic examinations and drugs, health education programs, as well as expertise in hepatitis $\mathrm{C}$, and other psychosocial services related to the person's health journey (for instance, taking care of someone's cat(s) while they are hospitalized). The main territory serviced by the cooperative comprises of SaintRoch and Saint-Sauveur neighbourhoods in Quebec City's Lower Town. However, the SABSA team agrees to provide care to people who live outside these strict geographic boundaries. Although just over half of the visitors in 2017 live in central neighbourhoods of Quebec City, many reside in the suburbs, in other cities of the province or are homeless.[25] The community relates here not only to a local context, but also to an experiential context, in the sense that SABSA's clientele includes relatively unaffiliated people that share common conditions of existence, for instance a more "disadvantaged" living environment or issues with mental health, addiction or chronic diseases.[25] The cooperative solidarity program allows full autonomy to the SABSA workers regarding the priorities, the process and the services provided. However, this autonomy is constrained by limited funding. SABSA, which advocates for the development of a provision of accessible and free health care, does not charge any fee to create a file nor costs for the consultations. If the person does not have a health insurance card, they will be welcomed and treated at SABSA all the same.

In Quebec, this model is innovative because caregiving relies on specialized nurse practitioners who are practising in full autonomy without physicians present on-site. Physicians still partake in the trajectory of care and nurses can refer to them if needed. The team also consists of one psychosocial support worker, nurse clinicians, and other HCPs.[23,26] A specialized nurse practitioner on the front line carries out the prescription for diagnostic examinations and drugs, take care of common health issues (such as otitis, urinary tract infections or pneumonia) as well as chronic disease and pregnancy. In this clinical practice framework, the physician's expertise is neither dominant nor exclusive, unlike mainstream healthcare framework (as evidenced by the necessity to transit by them to access other professional services). This transfer of power underlies a particular political resonance. These conditions can help to detach from the biomedical perspective, in order to adopt a humanistic and pragmatic philosophy of care.

Normative nature of the health path

The humanistic and pragmatic philosophy adopted by the SABSA cooperative fosters management by the individuals. The humanistic approach articulates care around the priorities as well as the concerns expressed by the person. The workers or volunteers will act as a guide or an advisor to develop an 
intervention plan together that will best meet the person's needs. In this sense, we believe that the SABSA cooperative caregivers are part of the normative approach of the person in a vulnerable situation. Rather than judging them against moral values involving bending the individual's will within the frameworks of the socially prescribed normality, the people at SABSA, through an ethical position that demands to listen to the person's story, supports them in their life path, and in the interstices of their social bonds. The pragmatic approach implies to accept deviations from the prescribed, moral or social norm and to listen to the norm(s) corresponding to the milieu they belong to. The focus is similar to an approach of harm reduction used outside the scope of public health which aims to protect the population. The primary objective is to respect the trajectory of the person who suffers and to act with concern and respect for the subject's life path. In other words, there is no persuasive speech held about a behavioural change (e.g., smoking cessation). The intervention rather aims to support the person in their choice by recognizing their decision-making power, which is necessarily rooted in the social or prescribed norms of the milieu they belong to. The psychosocial support worker, for example, is integrated into the people's living milieu in order to mobilize the meaning from their singular experience so to match the care provided with the needs expressed. These needs can include to organize material possessions, to take care of the person's pets or to find a new housing.[25] The SABSA cooperative has the flexibility to adapt to the variety of life experiences and provide services tailored to the reality of its members.

\section{Deployment of normativity in a community}

Two elements foster the deployment of normativity in a community. First, and similarly to the CCPSC, the cooperative solidarity program allows citizens and caregivers to play a significant role in the organization by giving them a voice in terms of direction and decision making concerning the provision of health care and services.[25] This implies recognition of the subject's autonomy: each individual going through their ordeal knows best what is important to them. The place attributed to citizens and caregivers thus takes on a particular political resonance that translates into a transfer of power to the individuals regarding the determination of not only what defines health in the community, but also the therapeutic approaches they need to improve health of the community. Second, the desire to provide services to a vulnerable clientele - for which we agree that the root causes of their health problems reside in their living conditions[20] implies a recognition of the milieu's impact on health. Since the citizen is part of one or several world(s), their health is inseparable from their context of emergence, from the community - this dynamic space where various influences meet, mingle and merge.

A thoughtful analysis has led us to think that such a conception of health is also investing other health care spaces. In the following section, we present this care space and emphasize how in this particular case, the political dimension of the living underlying the community health vitalistic perspective, can also address an ethical concern.

\section{Health's unique and subjective nature: The example of the Maison Michel-Sarrazin}

The Maison Michel-Sarrazin (MMS) is an end-of-life care centre founded in 1985 and located in Quebec City, where caregivers support people with cancer in the last stage of their lives.[27] The services provided are free of charge and dispensed equitably to those who meet the admission criteria (based on diagnosis and place of residence). The MMS health care team consists of HCPs from various disciplines, including physicians, pharmacists, nurses, social workers, one psychologist, one occupational therapist, one physiotherapist, and one nutritionist. Volunteers complement the health care team by assisting "the nursing staff in providing care and a comforting presence for patients and family members [free translation]".[27] In addition to its mission to deliver end-of-life care to patients and their family members, the MMS operates a day centre that welcomes patients and their loved ones on a daily basis. The day centre provides services and offers a variety of activities including professional services and complementary therapies (e.g., individual or group psychosocial support, massage therapy, and artistic expression) as well as various events animated by volunteers (e.g., listening and practice of music, discussions, meals, and relaxation). As opposed to the prior example, the Maison Michel-Sarrazin is not a CHC according to the CACHC's description,[8] but is instead a not-for-profit private hospital centre, which activities are funded in part by public funding, but more importantly by charitable donations from the community.[28] Nevertheless, its philosophy of care, comprehensive and humanistic, presents several common points with a vitalistic approach to community health, as to the unique and normative nature of health experienced in an end-of-life context.

The uniqueness of the lived experience

At the MMS, the types of care provided focus on the uniqueness of experience lived by both the people in end-of-life and their family members. Health is understood as an entirely subjective and unique phenomenon, by the recognition of the uniqueness 
and the specific identity of each person. Death is not a failure at life or the result of an undefeated pathology, but rather the ultimate experience of life, a state of transformation. Believing in the uniqueness of each person also means to believe in their potential as a human being to evolve up until the end and in their ability to decide in which living conditions they want to end their life, whenever accommodating is possible.[29] The end-of-life experience can give rise to various emotional, behavioural, and social responses that are difficult to predict from one individual to another. The experience of grief also varies from person to person and from time to time and comprises several elements unique to each individual and to the context surrounding the loved one's death.[30] Time is also playing a role to the extent that every single day brings forth different needs, which translate into different types of care for each patient-caregiver dyad. Demands and aspirations regarding life change and evolve according to the intersubjective and mediated dialogue between sick people, family members and caregivers. Besides, individuals with cancer are not described as patients or sick people per se, but rather as house guests ("invités de la Maison"). This attention paid to the terminology demonstrates this concern to consider the individual as a whole, beyond the medical condition they are presenting. The word Maison, French for "house," also emphasizes the importance of welcoming people in their last "home."

\section{Deployment of a normative ability}

Here, Canguilhem's[6] words claiming that disease is not the absence of health and health is not the absence of disease take on their full meaning. Cancer represents a deviation from the accepted biological and social norm but does not necessarily mean poor health. End-of-life is thought of as a stage of life, death, as a natural process, and this perspective acts as a guiding principle for the delivery of care.[31] Endof-life stage is essentially a new living condition during which the person and their family members can exert their ability to adapt to new norms while remaining rooted to their living milieu. Considering the uniqueness of the lived experience, this can translate differently for everyone. For instance, the house guests can smoke, as long as they remain outside, and to bring their pet(s) with them. Also, they are free to choose what they eat, their varying tastes and wishes are taken into consideration. Adult grief groups offered by the MMS explore themes such as family and social life reorganization, among other things. Hence, a wife can seek to cope with the identity change that arises from the death of her husband (status changing from married to widow) in order to feel more at ease with her new reality and while interacting with her social circle. While MMS's caregivers deliver care and interventions that aim to promote adaptation among the guests and their family members, they do not act solely as outside witnesses. Because they play an active role in this dynamic and in their social milieu, they become a part of the normative activity deployed and may possibly end up questioning their own conception of health due to its influence.

The example of the MMS illustrates how a health vitalistic approach allows us to think outside the biomedicine prescriptive framework while not confining community health to a particular organizational and institutional context. Although the community is not formally involved in the governance of this centre, the MMS general philosophy allows space to welcome the subjectivity in the lived experience of the individuals and conceive death as a normative experience of life.

\section{Conclusion}

An epistemological and ontological reflection on how the idea of community health is constructed appears helpful to illustrate what characterizes health care practices in $\mathrm{CHCs}$. Community health revisited through Georges Canguilhem's perspective allows us to go beyond the dominant biomedical model in health care services within health institutions, and to possibly consider innovative ones. Indeed, this reflexive process highlights the necessity for community HCPs to reframe the concept of "care" outside its strictly curative intents. CHCs contribute to health by acknowledging the individual's unique relationship with their milieu and the rules of propriety, as a biological, social, cultural and economic entity, that allows them to fit within the one or several communities they belong to. The vitalistic approach to health recognizes the impact on health of the social and cultural conditions, that are also fundamentally political.[32,33] This perspective can also apply in contexts where the vulnerability is expressed differently, as is the case at the MMS. Thus, community health initiatives can affect different unaffiliated populations, whose needs are not met by the mainstream healthcare systems. The centres provided as examples in this chapter illustrate how this idea of community health can express itself in multiple ways according to different organizational contexts. Interestingly, these sites are operating in the margins of Quebec's health system, one as a non-profit organization, and the other as a private hospital centre. This exclusion from the system could foster the adoption of a perspective going beyond biomedical aspects, but not without contingencies. Among others, limited financial resources can be particularly restrictive due to reduced operational effectiveness, the inability to compensate the professionals for their work and, most importantly, the limited number of patients who can benefit from care and 
services. Beyond the difficulties the development of such an approach could encounter, this paper is mostly intended as an invitation to all students, practitioners, decision makers, as well as managers, to consider the idea of health differently and to think about practical implications of such an analysis. When thinking about the best way to improve health in the community, the first question to ask could be which "health" are we talking about. A community health vitalistic approach could have multiple implications in the field in terms of practice - as we discussed at length in this paper -, but also in terms of teaching and research. This perspective could serve as a milestone for field definition and theoretical development as well as for the designation of research objects and methodology that truly embrace the complexity that underlies health situations.

\section{References}

1.Jourdan D, O'Neill M, Dupéré S, Stirling J. Community health: where do we stand after forty years? Public Health 2012; 24(2): 165-178.

2.Preamble to the Constitution of WHO as adopted by the International Health Conference, New York, 19 June - 22 July 1946; signed on 22 July 1946 by the representatives of 61 States (Official Records of WHO, no. 2, p. 100) and entered into force on 7 April 1948.

3.World Health Organization (1986). Ottawa Charter for Health Promotion. Geneva.

4.Vonarx N, Desgroseilliers V. Santé communautaire et santé publique : des différences profondes. In : Desgroseilliers $V$, Vonarx N, Guichard A, Roy B (eds). La santé communautaire en 4 actes. Québec : Presses de I'Université Laval, 2016 : 9-23.

5.Canguilhem G. Le normal et le pathologique. Paris : Presses Universitaires de France, 1966.

6.Canguilhem G. The Normal and the Pathological. New York: Zone Books, 1991. (Original manuscript published in 1966 under the title Le normal et le pathologique. Paris : Presses Universitaires de France).

7.Mayol P. (1998). Propriety. In: De Certeau M, Giard L, Mayol $\mathrm{P}$ (eds.), The Practice of Everyday Life, Volume 2. Minneapolis: University of Minnesota Press, 1998: 15-34.

8.Canadian Association of Community Health Centres. (2019). About Community Health Centres. Available from https://www. cachc.ca/about-chcs/.

9.Klein A. La santé comme norme de soin. Philosophia
Scientiae 2008; 2: 213-227.

10. Herzlich C. Santé et maladie. Analyse d'une représentation sociale. Walter de Gruyter GmbH \& Co KG, 1969.

11.Illich I. Medical Nemesis: The Expropriation of Health. London: Calder \& Boyars, 1975.

12.Evans RG, Barer ML, Marmor TR. Why are some people healthy and others not? The determinants of the health of populations. New-York: Transaction Publishers, 1994.

13.Contandriopoulos A-P. Éléments pour une "topographie " du concept de santé. Ruptures, Revue Transdisciplinaire En Santé 2006; 11(1) : 86-99.

14.Desgroseilliers V, Vonarx N. Retrouver la complexité du réel dans les approches théoriques de promotion de la santé : transiter par l'identité du sujet. Santé publique 2014; 26 : 17-31.

15.Perron A. La construction des personnes comme enjeu de santé publique et de santé communautaire. In : Desgroseilliers V, Vonarx N, Guichard A, Roy B (eds). La santé communautaire en 4 actes. Québec : Presses de I'Université Laval, 2016 : 2933.

16.Le Bossé Y. Sortir de l'impuissance, volume 2 : Aspects pratiques. Québec : Éditions Ardis, 2017.

17.Vonarx N. Santé et maladie au cinéma. Québec, LIBER, 2018.

18. Health Canada. Canada Health Act Annual Report 20162017. Available from: https://www.canada.ca/content/dam/ hc-sc/documents/services/publications/health-systemservices/canada-health-act-annual-report-2016-2017/ canada-health-act-annual-report-2016-2017-eng.pdf.

19.Conill EM, O'Neill M. The concept of community health: elements of international comparison [Article in French]. Canadian Journal of Public Health 1984; 75(2): 166-175.

20.Plourde A. La santé communautaire à la lumière du modèle de la Clinique communautaire de Pointe-Saint-Charles. In : Desgroseilliers V, Vonarx N, Guichard A, Roy B (eds). La santé communautaire en 4 actes. Québec : Presses de l'Université Laval, 2016 : 24-28.

21.Le collectif CourtePointe. Pointe Saint-Charles : un quartier, de femmes, une histoire communautaire. Montréal : Les Éditions du Remue-Ménage, 2006.

22.Plourde A. CLSC ou GMF? Comparaison des deux modèles et impact du transfert de ressources. Institut de recherche et d'informations socioéconomiques, 2017. 
23.Coopérative de solidarité SABSA. Historique. Available from: https://www.sabsa.ca/historique/.

24.Contandriopoulos D, Duhoux A, Perroux M, Roy B, Cockenpot A, Labarthe J, Mattmann S, Lardeux A, Lachapelle K. Rapport préliminaire : La Coopérative de solidarité SABSA. Available from https://www.pocosa.ca/wp-content/uploads/2015/09/ Sabsa-FINAL.pdf

25.Coopérative de solidarité SABSA. Rapport annuel des activités 2017. Available from: http://www.coopsabsa.com/

26. Mattmann S. Les contextes d'émergence des coopératives de santé et de services sociaux Le cas de la Coopérative de solidarité SABSA à Québec (master's thesis). Université Laval, Québec, 2018.

27.Maison Michel-Sarrazin. La vie à la Maison. Available from: http://www.michel-sarrazin.ca/la-vie-a-la-maison/

28.Fondation de la Maison-Michel-Sarrazin. Rapport annuel 2017-2018. Available from: https://indd.adobe.com/ view/58d82bc4-8cca-4d7d-a061-679c11cce615

29.Maison Michel-Sarrazin. Valeurs et philosophie de la Maison Michel-Sarrazin (Code d'éthique). Available from: http://www.michel-sarrazin.ca

30.Shuchter RS, Zisook S. The course of normal grief. In: Stroebe MS, Stroebe W, Hansson RO. (eds). Handbook of bereavement: Theory, research, and intervention. Australia: Cambridge University Press, 1993.

31.Maison Michel-Sarrazin. Politique et programme de soins palliatifs et de fin de vie à la Maison Michel-Sarrazin. Available from: http://www.michel-sarrazin.ca

32.Fassin D. Entre politiques du vivant et politiques de la vie : pour une anthropologie de la santé. Anthropologie et sociétés 2000; 24(1) : 95-116.

33.Roy B. (2002). Sang sucré, pouvoir codés et médecine amère. Diabète et processus de construction identitaire: Les dimensions socio-politiques du diabète chez les Innus de Pessamit (doctoral thesis). Université Laval, Québec, 2002.
Acknowledgements

This work was supported by Vanier Canada Graduate Scholarship awarded to EB. The authors would like to thank Chloé GenestBrunetta for her linguistic revision of the manuscript. The authors declare no conflict of interest.

To contact the authors:

Elisabeth Beaunoyer M.A., Ph.D.(c)

Université Laval

Faculté des sciences infirmières

1050 Avenue de la Médecine

Québec, Québec, G1V 0A6

Canada

E-mail: elisabeth.beaunoyer.1@ulaval.ca

Valérie Desgroseilliers, M.A., Ph.D.(c)

Université Laval

Faculté des sciences infirmières

Nicolas Vonarx Ph.D.

Université Laval

Faculté des sciences infirmières

Bernard Roy Ph.D.

Université Laval

Faculté des sciences infirmières 